\title{
Demo: A Social Wearable that Affords Vulnerability
}

\author{
Ella Dagan \\ University of California, Santa Cruz \\ Santa Cruz, CA, USA \\ ella@ucsc.edu
}

\author{
Ferran Altarriba Bertran \\ University of California, Santa Cruz \\ Santa Cruz, CA, USA \\ faltarri@ucsc.edu
}

\author{
Elena Márquez Segura \\ Department of Informatics and Media, \\ Uppsala University \\ Uppsala, Sweden \\ elena.marquez@ucsc.edu
}

\author{
Miguel Flores \\ University of California, Santa Cruz \\ Santa Cruz, CA, USA \\ mflore048@gmail.com
}

\author{
Katherine Isbister \\ University of California, Santa Cruz \\ Santa Cruz, CA, USA \\ katherine.isbister@ucsc.edu
}

\begin{abstract}
We present 'True Colors': a social wearable prototype designed to augment co-located social interaction of players in a LARP (live action role play). We designed it to enable the emergence of rich social dynamics between wearers and non-wearers. True Colors is Y-shaped, worn around the upper body, and has front and back interfaces to distinguish between actions taken by the wearer (front), and actions taken by others (back). To design True Colors, we followed a Research-through-Design approach, used experiential qualities and social affordances to guide our process, and codesigned with LARP designers. 13 True Colors wearables were deployed in a 3-day LARP event, attended by 109 people. From all the functionalities and interactivity the device afforded, players gravitated towards ones that emphasized the social value of experiencing vulnerability as a prompt to get together. This project was recently presented in CHI '19 [1] and may offer useful insights to others in the UbiComp/ISWC community who develop technology to support co-located social experience.
\end{abstract}

\section{CCS CONCEPTS}

\section{- Human-centered computing $\rightarrow$ HCI theory, concepts} and models.

\section{KEYWORDS}

Social wearables; wearables; RtD; LARP; co-located social play; embodied interaction; social touch.

Permission to make digital or hard copies of part or all of this work for personal or classroom use is granted without fee provided that copies are not made or distributed for profit or commercial advantage and that copies bear this notice and the full citation on the first page. Copyrights for thirdparty components of this work must be honored. For all other uses, contact the owner/author(s).

UbiComp/ISWC '19 Adjunct, September 9-13, 2019, London, United Kingdom (c) 2019 Copyright held by the owner/author(s).

ACM ISBN 978-1-4503-6869-8/19/09.

https://doi.org/10.1145/3341162.3350767
ACM Reference Format:

Ella Dagan, Ferran Altarriba Bertran, Elena Márquez Segura, Miguel Flores, and Katherine Isbister. 2019. Demo: A Social Wearable that Affords Vulnerability. In Adjunct Proceedings of the 2019 ACM International foint Conference on Pervasive and Ubiquitous Computing and the 2019 International Symposium on Wearable Computers (UbiComp/ISWC '19 Adjunct), September 9-13, 2019, London, United Kingdom. ACM, New York, NY, USA, 2 pages. https: //doi.org/10.1145/3341162.3350767

\section{INTRODUCTION}

True Colors is a social wearable, i.e. a wearable that augments co-located social interaction [6]. Our main goal in this project was to design a device that enhanced social interaction and enabled the emergence of rich social dynamics between wearers and non-wearers. To this end, the front interface was designed to empower the wearer to initiate action, while the back was designed for others to use. We were inspired by prior work on technology co-creation with expert design communities [5, 6]. LARP (live action role play) designers are experts in designing narrative and environments that support rich social experience for their players by utilizing technological and non-technological objects $[7,9]$. We created True Colors by using a Research-throughDesign (RtD) approach $[3,10,11]$ and co-creation [8] with Event Horizon (EH)'s LARP designers of New Gyr LARP [4]. A video introduction of the project can be accessed here: https://youtu.be/BBAlV4MCY04.

\section{DEMO SESSION AT UBICOMP/ISWC}

We will bring two True Colors prototypes with us. One will stay near our demo booth at all times (either on a mannequin or on the presenter). We will use it to explain and demo our True Colors design to visitors, who will be able to see and touch it. The other device will be available for participants to try on and interact with. We will invite those who are willing to try to do so with somebody else, and will show them its functionalities, and how they can interact with each other's wearable. This type of experience will last about 5 


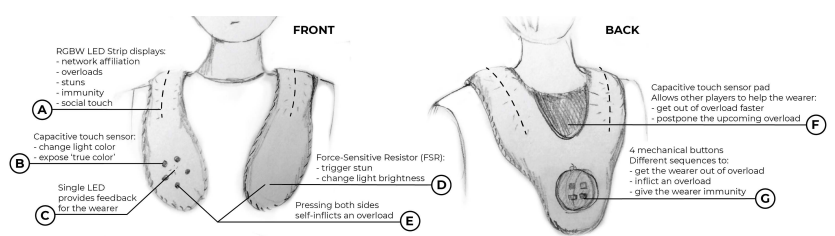

Figure 1: Final design illustration. ${ }^{\odot}$ Ella Dagan. Video description of the wearable: https://youtu.be/BBAlV4MCY04

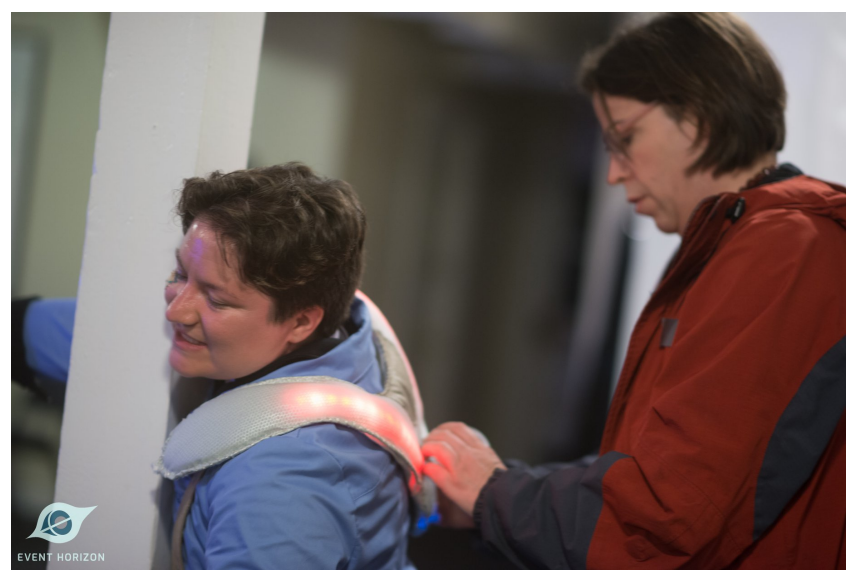

Figure 2: True Colors wearable displaying in-game 'Overload' state. ${ }^{\odot}$ Event Horizon.

minutes. By demoing, and having attendees experience it, we can start a discussion with experts in multiple relevant disciplines, grounded in their embodied experience, about potential uses of a social wearable like True Colors, outside the realm of games/play. The UbiComp/ISWC conference is the perfect venue to open this conversation.

To create an efficient flow of people through the demo to avoid queues, our booth will have one True Colors on display, printed demo submissions, a video played on a loop on a tablet/laptop that we will bring with us, and leaflets with key design aspects. The explanation about True Colors at the booth will not take more than 2 minutes. If too many people crowd our demo at the same time, they will likely hear the explanation, observe others using the wearables, or perhaps watch the video playing on a loop. Attendees who would be interested in trying out the demo while the booth is busy would be invited to come later for a more hands-on experience.

\section{PRESENTATION HISTORY}

- True Colors was demoed at the Exploratorium After Dark Event in San Francisco. https://tinyurl.com/ y25tyglf

- True Colors was demoed during a workshop at DIS '19 https://dis2019.com/accepted-workshops/
- True Colors design was the focus of a CHI '19 paper [1]. Deployment photos on Event Horizon's social media: https://tinyurl.com/y4x2vmsz.

- True Colors design was included as one of two design examples in DIS '19 paper [2].

\section{ACKNOWLEDGMENTS}

We thank Event Horizon team and New Gyr's participants. We thank all who helped us produce copies of the design.

\section{REFERENCES}

[1] Ella Dagan, Elena Márquez Segura, Ferran Altarriba Bertran, Miguel Flores, and Katherine Isbister. 2019. Designing 'True Colors': A Social Wearable That Affords Vulnerability. In Proceedings of the 2019 CHI Conference on Human Factors in Computing Systems (CHI '19). ACM, New York, NY, USA, Article 33, 14 pages. https://doi.org/10.1145/ 3290605.3300263

[2] Ella Dagan, Elena Márquez Segura, Ferran Altarriba Bertran, Miguel Flores, Robb Mitchell, and Katherine Isbister. 2019. Design Framework for Social Wearables. In Proceedings of the 2019 on Designing Interactive Systems Conference (DIS '19). ACM, New York, NY, USA, 1001-1015. https://doi.org/10.1145/3322276.3322291

[3] William Gaver. 2012. What Should We Expect from Research Through Design?. In Proceedings of the SIGCHI Conference on Human Factors in Computing Systems (CHI '12). ACM, New York, NY, USA, 937-946. https://doi.org/10.1145/2207676.2208538

[4] Event Horizon. 2018. World Database. Retrieved December 31, 2018 from http://www.eventhorizonlarp.com/world-database.html

[5] Katherine Isbister, Elena Márquez Segura, Suzanne Kirkpatrick, Xiaofeng Chen, Syed Salahuddin, Gang Cao, and Raybit Tang. 2016. Yamove! A movement synchrony game that choreographs social interaction. Human technology 12 (2016).

[6] Elena Márquez Segura, James Fey, Ella Dagan, Samvid Niravbhai Jhaveri, Jared Pettitt, Miguel Flores, and Katherine Isbister. 2018. Designing Future Social Wearables with Live Action Role Play (Larp) Designers. In Proceedings of the 2018 CHI Conference on Human Factors in Computing Systems. ACM, 462.

[7] Elena Márquez Segura, Katherine Isbister, Jon Back, and Annika Waern. 2017. Design, appropriation, and use of technology in larps. In Proceedings of the 12th International Conference on the Foundations of Digital Games. ACM, 53.

[8] Elizabeth B.-N. Sanders and Pieter Jan Stappers. 2008. Co-creation and the new landscapes of design. CoDesign 4, 1 (Mar 2008), 5-18. https://doi.org/10.1080/15710880701875068

[9] David Simkins. 2015. The Arts of LARP: Design, Literacy, Learning and Community in Live-Action Role Play. McFarland.

[10] John Zimmerman, Jodi Forlizzi, and Shelley Evenson. 2007. Research Through Design As a Method for Interaction Design Research in HCI. In Proceedings of the SIGCHI Conference on Human Factors in Computing Systems (CHI '07). ACM, New York, NY, USA, 493-502. https://doi. org $/ 10.1145 / 1240624.1240704$

[11] John Zimmerman, Erik Stolterman, and Jodi Forlizzi. 2010. An Analysis and Critique of Research Through Design: Towards a Formalization of a Research Approach. In Proceedings of the 8th ACM Conference on Designing Interactive Systems (DIS '10). ACM, New York, NY, USA, 310-319. https://doi.org/10.1145/1858171.1858228 